\title{
ANALISIS SEBARAN DAN KOMPOSISI JENIS IKAN KAKAP MERAH HASIL TANGKAPAN TRA WL PADA MUSIM PERALIHAN II DI LAUT ARAFURA
}

\author{
Adi Surahman', Riena F. Telussa², Khairul Amri³ \\ Jurusan Pemanfaatan Sumberdaya Perikanan, \\ Fakultas Perikanan dan Ilmu Kelautan Universitas Satya Negara Indonesia \\ Jln. Arteri Pondok Indah No. 11 Jakarta 12240 \\ E-mail: adirizky_kkp@ymail.com
}

\begin{abstract}
ABSTRAK
: Potensi Laut Arafura yang besar tidak terlepas dari isu dan permasalahan pemanfaatan perikanan laut. Kegiatan penangkapan ikan secara intensif telah memberikan tekanan yang besar terhadap lingkungan perairan Laut Arafura (Badrudin et al., 2008). Laut Arafura terkenal kaya sumberdaya ikan, perkembangan pesat dan intensitas penangkapan yang meningkat dari armada perikanan pukat udang dan pukat ikan bukan saja berdampak pada penurunan tajam stok ikan demersal dan udang. Data yang diambil pada penelitian ini merupakan data primer. Data primer merupakan data yang diambil secara langsung pada lokasi penelitian Laut Arafura menggunakan wahana kapal KR Baruna Jaya IV yang kemudian dicatat dan diproses dengan menggunakan software Surfer 12 secara horizontal. Komposisi jenis ikan kakap yang tertangkap pada musim peralihan II di periaran Laut Arafura terdiri dari delapan jenis yaitu Lutjanus russelli, $L$. malabaricus, L. vitta, L. sebae, L. johni, L. carponotatus, L. monostigma dan L. lutjanus. Jenis ikan kakap yang paling dominan tertangkap adalah jenis L. russelli yang mencapai 51,47\% dari total ikan kakap yang tertangkap. Jenis ikan kakap yang dominan kedua ditempati oleh jenis $L$. malabaricus yaitu sebesar $31,77 \%$, sedangkan jenis ikan kakap lainnya diperoleh kurang dari 10 $\%$
\end{abstract}

Keywords: Sebaran,Komposisi Hasil Tangkapan Trawl, Laut Arafura

\section{PENDAHULUAN}

Potensi Laut Arafura yang besar tidak terlepas dari isu dan permasalahan pemanfaatan perikanan laut. Kegiatan penangkapan ikan secara intensif telah memberikan tekanan yang besar terhadap lingkungan perairan Laut Arafura (Badrudin et al., 2008). Laut Arafura terkenal kaya sumberdaya ikan, perkembangan pesat dan intensitas penangkapan yang meningkat dari armada perikanan pukat udang dan pukat ikan bukan saja berdampak pada penurunan tajam stok ikan demersal dan udang (Sularso, 2005).

Efisiensi Trawl akan ditingkatkan sebanding dengan ukuran alat, semakin besar alat juga mengandung arti memerlukan energi yang lebih besar, sebaliknya semakin besar Trawl akan memerlukan kapal yang bertenaga besar agar ekonomis, hal ini akan menimbulkan kesulitan dalam pengembangan lanjutan yang diiringi dengan semakin meningkatnya bahan-bahan bakar (Ardidja, 2007).

Laut Arafura secara geografi merupakan perairan berbatasan dengan perairan Australia. Sebagian besar dari perairan ini merupakan bagian dari Dangkalan Sahul. Berbagai jenis ikan demersal laut dalam menempati perairan ini. Jenis-jenis kakap merah (Lutjanus sp) umumnya 
menempati perairan dengan kedalaman 50-180 m dan mengalami penurunan hasil tangkapan secara drastis pada 2006 (Blaber et al., 2005).

\section{MATERI DAN METODE}

Penelitian analisis sebaran dan komposisi jenis ikan kakap merah hasil tangkapan trawl pada musim peralihan II di Laut Arafura. Telah dilaksanakan pada bulan Oktober 2016 dengan menggunakan kapal riset Baruna Jaya IV milik BPPT

Lokasi stasiun penangkapan ditentukan dengan memperhatikan kedalaman dan mempertimbangan kelayakan dasar perairan untuk trawling. Penangkapan dilakukan sebanyak satu kali pada setiap lokasi stasiun. Hasil tangkapan di masing-masing stasiun disortir kemudian ditimbang dan dihitung jumlahnya berdasarkan jenis untuk mengetahui komposisi jenisnya.

\section{METODE PENELITIAN}

Data yang diambil pada penelitian ini merupakan data primer. Data primer merupakan data yang diambil secara langsung pada lokasi penelitian Laut Arafura menggunakan wahana kapal KR Baruna Jaya IV yang kemudian dicatat dan diproses dengan menggunakan software Surfer 12 secara horizontal.

\section{ANALISIS DATA}

Data hasil tangkapan diolah menggunakan software Excel selanjutnya ditabulasi dan ditampilkan dalam grafik sederhana agar diketahui variasinya. Data hasil tangkapan trawl per stasiun sampling (jumlah hasil tangkapan, komposisi jenis dan sebaran).

Posisi keberadaan ikan disesuaikan dengan posisi koordinat GPS (Global Positioning System) kapal terhadap lintasan penarikan trawl. Beberapa asumsi yang digunakan pada penentuan sebaran ikan secara horizontal antara lain posisi koordinat kapal pada saat trawl mulai dilakukan penarikan dijadikan sebagai posisi koordinat keberadaan ikan, panjang lintasan trawl diasumsikan menggambarkan area yang sama dan aspek operasional alat tangkap dianggap tidak memberikan pengaruh yang nyata. Data posisi koordinat yang diperoleh dan data hasil tangkapan trawl berdasarkan kedalaman kemudian divisualisasikan dengan menggunakan software Surfer 12.

Sebaran ikan kakap didasarkan pada kelimpahan ikan demersal baik secara horizontal (berdasarkan stasiun pengamatan) maupun vertikal (berdasarkan kedalaman perairan). Untuk menghitung kepadatan stok, maka terlebih dahulu dihitung luas daerah yang disapu trawl dengan persamaan : $\mathrm{a}=\mathrm{S} \times \mathrm{E}$

Lebar bukaan mulut jaring trawl ditentukan dengan beberapa cara yaitu dengan menggunakan nilai fraksi empiris $\left(\mathrm{f}_{2}\right)$, yang biasa digunakan oleh beberapa peneliti terdahulu. Di kawasan Asia Tenggara nilai $\mathrm{f}_{2}$ berkisar antara 0,4 (Shindo, 1973) sampai 0,66 (SCSP, 1978). Klim (1976) menggunakan nilai $\mathrm{f}_{2}=0,6$; Pauly (1980) memberikan nilai $\mathrm{f}_{2}=0,5$, pendapat ini diambil dari Sparre P.; Siebren C, Venema (1999). Pada penelitian saat ini yang akan digunakan sebagai analisis ini adalah dengan nilai $\mathrm{f}_{2}=0,5$.

Sumber daya ikan yang tertangkap trawl dikelompokkan dan dipisahkan berdasarkan pada taksa famili, genus, spesies dan kelompok sumber daya ikan. Populasi ikan yang tertangkap selanjutnya dihitung jumlah individu dan ditimbang bobotnya sehingga didapatkan nilai laju tangkap (kg/jam). Referensi yang dijadikan acuan adalah Thomas Gloefelt-Tarp Patricia J. Kailola (1985). 
Komposisi hasil tangkapan dianalisis sebagai persentase perbandingan bobot hasil tangkapan ikan $(\mathrm{kg})$ antara satu spesies dengan spesies lainnya atau antara satu famili dengan famili lainnya, selanjutnya ditabulasi dan ditampilkan dalam grafik sederhana agar diketahui variasinya.

$$
X=\frac{n}{w} x 100 \%
$$

$\mathrm{X}=$ persentase hasil tangkapan per spesies

$\mathrm{N}=$ hasil tangkapan per spesies $(\mathrm{kg})$

$\mathrm{W}=$ hasil tangkapan total $(\mathrm{kg})$

\section{HASIL DAN PEMBAHASAN}

Sumber daya ikan yang tertangkap dibagi dalam 8 kelompok utama yakni :ikan demersal, ikan pelagis, udang (udang peneid, mantis, lobster ), krustase lain (kepiting/rajungan), ikan pari, ikan hiu, cephalopoda (cumi/sotong/gurita)dan kelompok sumber daya lain-lain (kekerangan, teripang, bulubabi, belut laut dan lainnya). Hasil identifikasi menunjukkan bahwa jumlah taksa seluruh sumber daya ikan yang tertangkap terdiri dari 378 spesies yang tergolong dalam 110 famili (Tabel 2). Jumlah spesies terbanyak diperoleh dari kelompok ikan demersal (244 spesies), kemudian disusul kelompok ikan pelagis (30 spesies), ikan lain-lain 28 spesies, udang 21 spesies sedangkan kelompok sumber daya yang lain masing-masing kurang dari 20 spesies.

Kelimpahan ikan kakap paling tinggi diperoleh di perairan bagian timur Kepulauan Aru yaitu pada stasiun 12 dengan kelimpahan rata-rata mencapai $4657.5 \mathrm{~kg} / \mathrm{km}^{2}$. Selanjutnya, kelimpahan tertinggi kedua diperoleh pada stasiun 5 yaitu sebesar $923.4 \mathrm{~kg} / \mathrm{km}^{2}$. Stasiun tersebut berada di bagian timur Laut Arafura yang berdekatan dengan daratan Papua, tepatnya di perairan selatan Agats. Kelimpahan ikan kakap yang berkisar antara 50 sampai $100 \mathrm{~kg} / \mathrm{km}^{2}$ tersebar di bagian timur-laut Kepulauan Aru (stasiun 15), bagian tenggara Kepulauan Aru (stasiun 4, stasiun 5 dan stasiun 7), serta di perairan selatan Timika (stasiun 13).

Secara umum, ikan kakap lebih banyak tersebar di area perairan Kepulauan Aru dibandingkan area perairan Papua. Hal ini disebabkan karena karakteristik ikan kakap yang cenderung berasosiasi dengan karang dan wilayah perairan Kepulauan Aru didominasi oleh habitat karang sedangkan perairan pesisir Papua cenderung didominasi oleh habitat pasir berlumpur.

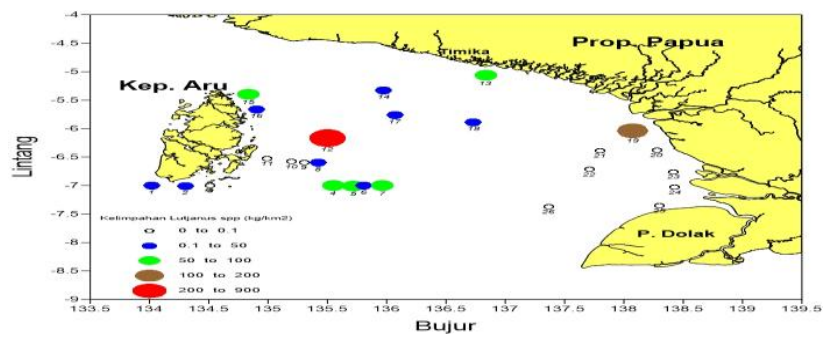

Gambar. Sebaran horizontal kelimpahan ikan kakap (Lutjanus sp) pada musim peralihan II di perairan Laut Arafura.

Jenis-jenis ikan kakap merah yang tertangkap trawl dengan menggunakan kapal KR Baruna Jaya IV pada saat musim peralihan II adalah sebagai berikut:

1. Lutjanus carponotatus (kakap gigi jarang) 
2. Lutjanus monostigma (kakap batu)

3. Lutjanus malabaricus (kakap merah)

4. Lutjanus johni (kakap jenaha)

5. Lutjanus sebae (kakap merah)

6. Lutjanus vitta (kakap kuning)

7. Lutjanus russelli (kakap sawo)

8. Lutjanus lutjanus (kakap garis kuning)

Ikan kakap merah merupakan bagian dari kelompok ikan demersal dari famili Lutjanidae dan marga Lutjanus. Ikan demersal yang tertangkap pada penelitian ini terdiri dari 63 famili dengan sepuluh famili yang memiliki komposisi paling besar terdiri dari Leiognatidae, Haemulidae, Nemipteridae, Mullidae, Gerreidae, Ariidae, Lutjanidae, Teraponidae, Lethrinidae, dan Scianidae.

Komposisi jenis ikan kakap yang tertangkap pada musim peralihan II di periaran Laut Arafura terdiri dari delapan jenis yaitu Lutjanus russelli, L. malabaricus, L. vitta, L. sebae, L. johni, L. carponotatus, L. monostigma dan L. lutjanus. Jenis ikan kakap yang paling dominan tertangkap adalah jenis $L$. russelli yang mencapai 51,47 \% dari total ikan kakap yang tertangkap. Jenis ikan kakap yang dominan kedua ditempati oleh jenis L. malabaricus yaitu sebesar 31,77 \%, sedangkan jenis ikan kakap lainnya diperoleh kurang dari $10 \%$ (Gambar 12). Ikan jenis $L$. russelli dan L. malabaricus menyusun komposisi tangkapan ikan kakap yang mencapai 83,42\%. Hal ini menunjukan bahwa kedua jenis ikan ini merupakan kelompok ikan kakap yang dominan diperoleh di perairan Laut Arafura pada musim peralihan II.

\section{Komposisi jenis ikan kakap}

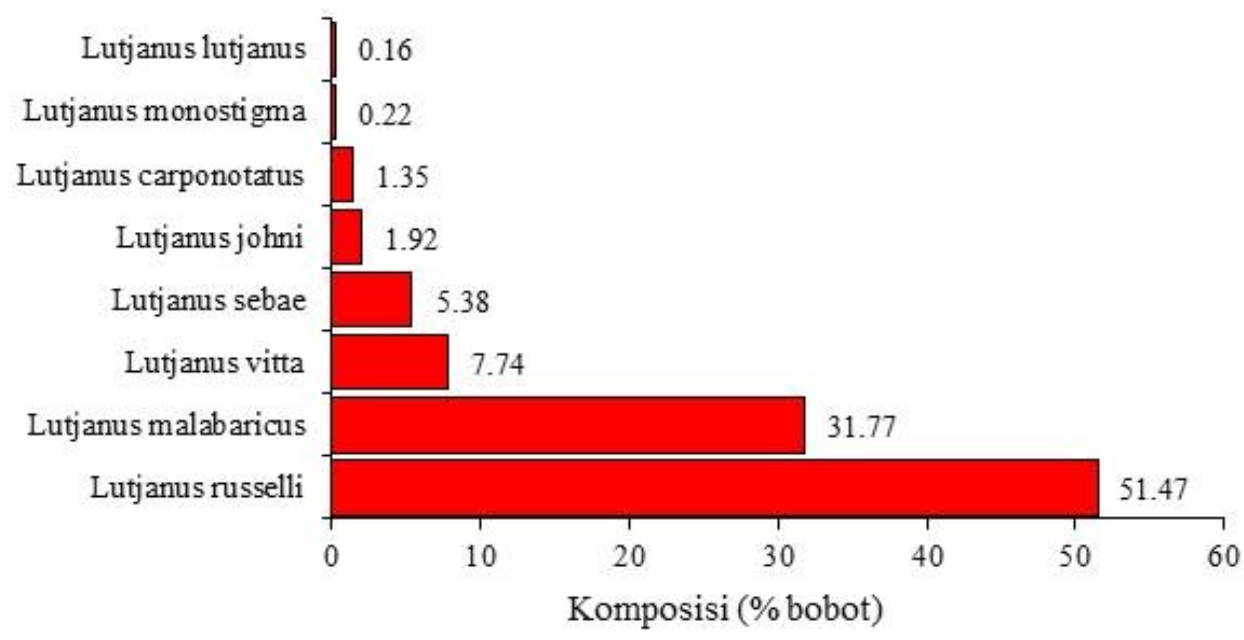

Gambar . Komposisi jenis ikan kakap hasil tangkapan trawl pada musim peralihan II di perairan Laut Arafura, 2016.

Jenis ikan kakap yang paling sedikit ditemukan di perairan Laut Arafura ini adalah jenis ikan kakap L. lutjanus dan L. monostigma yang mana berdasarkan bobot hasil tangkapan mereka hanya menyumbang masing-masing kurang dari 0,5\% total tangkapan ikan kakap. Jenis ikan kakap yang paling dominan diperoleh yaitu ikan kakap L. russellii, yang memiliki karakteristik 
sebaran habitat yang luas mulai dari perairan pesisir pantai sampai perairan lepas pantai, bahkan ikan-ikan muda banyak ditemukan di perairan estuari/magrove dan paling banyak ditemukan pada kedalaman $20 \mathrm{~m}$ sampai $50 \mathrm{~m}$ (Froese dan Pauly 2018). Karakteristik tersebut sesuai dengan karakteristik Laut Arafura, sehingga jenis ikan ini sangat dominan diperoleh pada di Laut Arafura.

\section{KESIMPULAN DAN SARAN}

\section{Kesimpulan}

1. Ikan kakap jenis Lutjanus ditemukan menyebar di perairan Laut Arafura mulai dari pesisir Kepulauan Aru sampai keperairan Papua. Kelimpahan ikan kakap di area perairan Kepulauan Aru lebih tinggi dibandingkan perairan Papua. Ikan kakap tidak di temukan di perairan utara Pulau Dolak.

2. Komposisi jenis ikan kakap yang ditemukan di periaran Laut Arafura terdiri dari jenis Lutjanus russelli, L. malabaricus, L. vitta, L. sebae, L. johni, L. carponotatus, L. monostigma dan L. lutjanus. Jenis ikan kakap yang paling dominan ditemukan adalah jenis L. russelli yang mencapai 51,47 \% dan jenis L. malabaricus yang mencapai 31,77\%, sedangkan jenis lainnya ditemukan kurang dari $10 \%$.

\section{Saran}

1. Apabila ingin mempelajari komposisi hasil tangkapan trawl, harus lebih teliti dalam mengidentifikasi jenis ikan.

2. Sebagai masukan penerapan kebijakan bagi pemerintah dalam penerapan alat tangkap trawl.

\section{DAFTAR PUSTAKA}

Ardidja, Supardi. 2007. Kapal Penangkap Ikan. Jakarta: Sekolah Tinggi Perikanan Teknologi Penangkapan Ikan.

Badruddin, Nurhakim S, Prisantoso BI. 2008. Estimated unrecorded catch related to the number of licenced fishing vessel in the Arafura Sea. Ind. Fish. Res. J. Vol. 14 (1) : 25-31

Blaber, S.J.M., Dichmont, C.M., Buckworth, R.C., Badruddin, Sumiono, B., Nurhakim, S., Iskandar, B., Fegan, B., Ramm, D.C. \& J.P Salini. 2005.

Shared Stocks of snappers (Lutjanidae) in Australia and Indonesia: Integrating biology, population dynamics and socio-economic to examin management scenarios. Review in Fish Biology and Fisheries. 15:1 1 1-127.

Fujaya, Y. 2004. "Fisiologi Ikan (Dasar Pengembangan Teknik Perikanan)". PT. Rineka Cipta : Jakarta.

Food and Agriculture Organization. 1995. Methodology Manual: Measurement of Fissing Gear Selectivity. FAO. Rome.4-24-4-27. 
Grimes CB. 1987. Reproductive biology of the Lutjanidae: a review. In Polovina, JJ \& Ralston S (eds). Tropical snappers and Groupers: Biology and Fisheries Management. Westview Press. Boulder and London. 239-294.

Gunarso, W. 1995. Mengenal Kakap Merah Komoditi Ekspor Baru Indonesia (tidak dipublikasikan). Fakultas Perikanan dan Ilmu Kelautan. Institut Pertanian Bogor. Bogor. 238 hal.

Naamin N. 1984. Dinamika Populasi Udang Jerbung (Penaeus merguiensis de Man) di Perairan Arafura dan Alternatif Pengelolaannya [disertasi]. Bogor: Fakultas Pasca Sarjana, Institut Pertanian Bogor, 281 hal.

Nedelec, C. \& J. Prado. 1990. Definition and classification of fissing gear catagories. FAO Fisheries Technical Paper No. 222. Rev.1. FAO. Rome 25-29.

Newman, S.J., M. Cappo \& D. Williams. 2000. Age, Growth, Mortality Rates, and corresponding yield estimates using otoliths of the tropical red snapper, Lutjanus erythropterus, L. malabaricus, and L. sebae, from the central Great Barrier Reef. Fisheries Research 48: 1-14.

Purwanto dan Nugroho D. 2010. Tingkat optimal pemanfaatan stok udang, ikan demersal, dan ikan pelagis kecil di Laut Arafura. J. Lit. Perikan. Ind. Vol. 16 (4) : 15 - 21

Sularso A. 2005. Alternatif pengelolaan perikanan udang di Laut Arafura. [disertasi]. Bogor: Fakultas Pascasarjana Institu Pertanian Bogor. 148 hal.

Sumiono, B. 2008. Trend hasil tangkapan sampingan (bycatch) pukat udang di Laut Arafura. Dalam Wijopriono, B. Sadhotomo, dan R. Zainy (editor). Sumberdaya, Pemanfaatan, dan Opsi Pengelolaan Perikanan di Laut Arafura. Biodynex 2. BPPL, Jakarta : 37-55.

Suprapto. 2008. Keragaan penangkapan ikan demersal di kawasan timur Indonesia yang berbasis di Probolinggo. BAWAL Vol. 2 (3): 123-131

Suryanto dan A.P. Widodo. 2011. Struktur dan Dinamika Armada Perikanan di Laut Arafura. Paper dipresentasikan pada Forum Perikanan Arafura, Jakarta, 8 Nopember 2011. Pusat Riset Perikanan Tangkap, Badan Riset kelautan dan Perikanan, Jakarta. 94 hal.

Wedjatmiko dan Sukarniaty. 2007. Kajian terhadap operasional kapal trawl di perairan Laut Arafura. BAWAL Vol. 1 (4): 93-101. 